\title{
PADRE 965.10
}

National Cancer Institute

\section{Source}

National Cancer Institute. PADRE 965.10. NCI Thesaurus. Code C2397.

Pan-DR epitope (PADRE) 965.10 is a helper peptide. PADRE peptides have been shown the capacity to deliver help for antibody responses in vivo. They were also found to be able to provide significant helper T-cell activity in vivo. Acts as an adjuvant. 